\title{
The Impact of Socioeconomic Factors in Retinoblastoma
}

\author{
Ardizal Rahman ${ }^{1}$, Desty Ria Tiffani ${ }^{2}$ \\ \{ardizalrahman@yahoo.com ${ }^{1}$, destyriatiffani@yahoo.com² ${ }^{2}$,
}

Biomedicine Doctoral Program, Ophthalmology Departement of Medical Faculty, Universitas Andalas, Padang, Indonesia ${ }^{1}$, Ophthalmology Departement of Medical Faculty, Universitas Andalas, Padang, Indonesia ${ }^{2}$

\begin{abstract}
Retinoblastoma is the most common malignant ocular tumor of childhood and one of the most common pediatric solid tumors. Delays in diagnosis are multi-factorial, including poor awareness by public and healthcare professionals, poor access to appropriate healthcare services, delays in referral process causing increased lag time and general socioeconomic problems. To investigate the effect of socioeconomic status on the extent of disease and outcomes of retinoblastoma. We retrospectively reviewed the medical record of all retinoblastoma patient presenting to Outpatient Clinic of Ophthalmology Department dr. M. Djamil General Hospital during 2003-2018. We obtained information on age, gender, clinical staging, management, and socioeconomic status of patients. In this retrospective study, medical records of 141 retinoblastoma patients were reviewed. Most of the patient was diagnosed with the late stage of retinoblastoma and diagnosed between the age of 3 to 4 years old $(43.26 \%)$. Protrusion of the eye was the most frequent presenting sign $(66,67 \%)$, while 43 patients $(30.50 \%)$ came with leukocoria during first time visit to the hospital. Most of the patient was treated with a combination of exenteration and chemotherapy $(43,97 \%)$ due to an advanced stage. Based on socioeconomic status, most patients came from either low or middle economic status. Due to delay in diagnosis, most patients were treated with exenteration in combination with radiotherapy/chemotherapy (43.26\%). Socioeconomic factors have a big role in the history and outcomes of retinoblastoma. It is required to improve human resources and facilities to provide better diagnosis and management of retinoblastoma in children.
\end{abstract}

Keywords: Intraocular tumor, Leucocoria, Retinoblastoma, Socioeconomic factors.

\section{Introduction}

Retinoblastoma is the most common malignant intraocular tumor found in children, with over $90 \%$ of cases diagnosed during the first five years of life. The incidence of retinoblastoma ranged from 15,000-18,000 live births. Clinical findings that often appear as signs of retinoblastoma include leukocoria, strabismus, red-eye and pain of the eye, and proptosis of the eye for severe cases. The survival rate of retinoblastoma is good if the optic nerve is not involved, and decreases as the tumor spread to lamina cribosa and or optic nerve. The severe case that involves intracranial invasion can cause death. The clinical staging of retinoblastoma found during visit or diagnosis determines the prognosis of retinoblastoma thus early detection is needed [1],[2],[3]. 
There is still a huge gap in survival rates between the developed and the developing countries. One major factor is the stage during the first presentation or diagnosis. In developing countries, advanced disease contributed to $30 \%-40 \%$ of all cases, whereas in developed nations, only $2 \%-5 \%$ of cases of RB had advanced disease. Hence, the survival rates were as high as $90 \%-99 \%$ in the developed nations, while only $50 \%$ of children with RB survived worldwide. This problem in developing countries was caused by poor educational level, low socioeconomic level, inadequate medical and health facility. [4],[5-7]

Several studies of retinoblastoma patients found that prevalence of retinoblastoma in a developing country is high. Several socioeconomic factors contributed to advanced stage at presentation due to delay in diagnosis, lack of access to healthcare facilities, ignorance about early signs, illiteracy, poverty, lack of trained personnel, dropouts from ongoing therapy, and inadequate infrastructure. Cultural factors also influence treatment decisions and their uptake. It also concludes that in developing countries, the long duration between clinical signs and the time when the patient is diagnosed contributes to the delayed in the diagnosis and poor outcomes. [4],[7]

Management of retinoblastoma includes not only to prevent blindness but also to prevent complication that can reduce patient's quality of life. Major purposes of the management of retinoblastoma now exceed to preserve the eyeball, sight and cosmetic, and most importantly to increase life expectancy. Surgical procedures of retinoblastoma patients, enucleation and exenteration, are performed based on clinical staging or apparent size and the spreading of the tumor. Other options such as photocoagulation, cryotherapy, chemotherapy, and radiotherapy can be done alone or in combination with surgical management. Nevertheless, one of the major factors that also contribute to the poor outcome of retinoblastoma in developing countries is the drop-out from therapy due to many reasons. [2],[3],[7],8]. To our knowledge, this is the first study that retrospectively reviewed the socioeconomic of retinoblastoma patients in West Sumatera, Indonesia.

\section{Materials and Methods}

\subsection{Design}

This retrospective descriptive study was based on the data obtained from patients medical record.

\subsection{Sample}

The study population was all patients diagnosed with Retinoblastoma who visited the ophthalmology department of Dr M.Djamil General Hospital Padang from 2003 until 2018. We included a medical record with a complete medical history, examination, ancillary test (Orbital CT scan and USG), and treatment planned. Patients suspected with Retinoblastoma but had an incomplete examination or came only during the first visit were excluded.

\subsection{Data Collections}

We collected information based on age, gender, diagnosis, clinical symptom, management and the family's socioeconomic background presented in the medical record. 


\section{Result}

There were 141 cases of retinoblastoma treated from 2003 to 2018 as provided in table 1 .

Table 1. Retinoblastoma patients distribution by gender.

\begin{tabular}{lcccc}
\hline \multirow{2}{*}{ Years } & \multicolumn{2}{c}{ Sexuality } & Frequency & \% \\
\cline { 2 - 4 } 2003 & Male & Female & 11 & $7.80 \%$ \\
2004 & 6 & 5 & 9 & $6.38 \%$ \\
2005 & 6 & 3 & 14 & $9.92 \%$ \\
2006 & 5 & 9 & 6 & $4.25 \%$ \\
2007 & 3 & 3 & 12 & $8.51 \%$ \\
2008 & 6 & 6 & 8 & $5.67 \%$ \\
2009 & 6 & 2 & 18 & $13.76 \%$ \\
2010 & 11 & 7 & 7 & $4.96 \%$ \\
2011 & 3 & 4 & 5 & $3.54 \%$ \\
2012 & 3 & 2 & 9 & $6.38 \%$ \\
2013 & 7 & 2 & 4 & $2.83 \%$ \\
2014 & 2 & 2 & 11 & $7.80 \%$ \\
2015 & 7 & 4 & 6 & $4.25 \%$ \\
2016 & 3 & 3 & 9 & $6.38 \%$ \\
2017 & 6 & 3 & 7 & $4.96 \%$ \\
2018 & 4 & 3 & 5 & $3.54 \%$ \\
Total & 2 & 3 & 141 & \\
\hline
\end{tabular}

Table 1 showed the demographics of retinoblastoma patient with more male patients $(56.73 \%)$ than female $(43.26 \%)$. Based on the age of presentation, we found most patients was brought to the hospital in the age of 3-4 years old.

Table 2. Retinoblastoma patients distribution by age.

\begin{tabular}{|c|c|c|c|c|c|c|c|c|c|c|c|c|c|c|c|c|c|c|}
\hline $\begin{array}{l}\text { Age } \\
\text { (year } \\
\text { s) }\end{array}$ & 气ิ̊ & 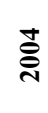 & 气̊̊ิ & ڤ్̀े & હે̊ิ & 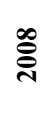 & 犬্ণิ & $\stackrel{\ominus}{\stackrel{7}{7}}$ & $\overline{\bar{\lambda}}$ & בั๋ & $\stackrel{m}{\stackrel{\sim}{二}}$ & $\stackrel{ \pm}{\stackrel{\Xi}{i}}$ & 号 & ํํㄱ & $\stackrel{\overline{\mathrm{N}}}{\mathrm{i}}$ & $\stackrel{\infty}{\stackrel{\sim}{~}}$ & $\begin{array}{l}\text { Freq } \\
\text {. }\end{array}$ & $\%$ \\
\hline$<1$ & 1 & 1 & 1 & 2 & 1 & 1 & 2 & 1 & - & - & 1 & 1 & - & 1 & - & - & 13 & $9.22 \%$ \\
\hline $2-3$ yo & 2 & 4 & 4 & 2 & 3 & 3 & 7 & 3 & 3 & 1 & - & 2 & 2 & 2 & 1 & 1 & 40 & $28.39 \%$ \\
\hline 3-4 yo & 5 & 2 & 7 & 2 & 4 & 2 & 6 & 3 & 2 & 7 & 2 & 6 & 3 & 4 & 3 & 3 & 61 & $43.26 \%$ \\
\hline $4-5$ yo & 1 & 2 & 1 & - & 1 & 2 & 1 & - & - & - & 1 & 1 & 1 & 2 & 2 & 1 & 16 & $11.34 \%$ \\
\hline$>5$ & 2 & - & 1 & - & 3 & - & 2 & - & - & 1 & - & 1 & - & - & 1 & - & 11 & $7.80 \%$ \\
\hline Total & 11 & 9 & 14 & 6 & 12 & 8 & 18 & 7 & 5 & 9 & 4 & 11 & 6 & 9 & 7 & 5 & 141 & \\
\hline
\end{tabular}


Based on table 2, most of the patient was diagnosed at the age of 3-4 years old (43.26\%), followed by the age of 2-13 years old. In term of lateralization, the retinoblastoma can affect one (unilateral) or both of the eyes (bilateral). Table 3 showed the lateralization of a patient with retinoblastoma in our hospital.

Table 3. Distribution of retinoblastoma patients based on lateralization.

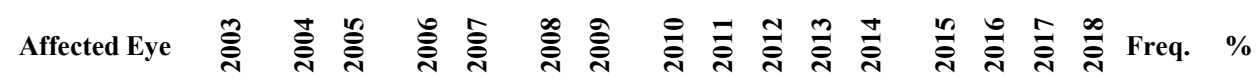

\begin{tabular}{lllllllllllllllllll}
\hline Unilateral & 7 & 7 & 9 & 5 & 8 & 7 & 15 & 6 & 5 & 7 & 3 & 8 & 4 & 6 & 5 & 4 & 106 & $75.18 \%$ \\
Bilateral & 4 & 2 & 5 & 1 & 4 & 1 & 3 & 1 & 0 & 2 & 1 & 3 & 2 & 3 & 2 & 1 & 35 & $24.82 \%$ \\
Total & 11 & 9 & 14 & 6 & 12 & 8 & 18 & 7 & 5 & 9 & 4 & 11 & 6 & 9 & 7 & 5 & 141 & \\
\hline
\end{tabular}

Based on table 3, most of the patient was diagnosed with unilateral retinoblastoma $(75.18 \%)$, the remain cases $(24.82 \%)$ were diagnosed with bilateral retinoblastoma. We decided clinical presentation retinoblastoma patient into 3 main signs; protrusion of the eye, leucocoria, and strabismus. Table 4 showed the distribution of patients based on clinical symptoms at presentation.

Table 4. The clinical symptoms of retinoblastoma patients during the first visit.

\begin{tabular}{|c|c|c|c|c|c|c|c|c|c|c|c|c|c|c|c|c|c|c|}
\hline Symptoms & ్ֻరి & ষ্ণ & ஜ্ণ & ஓ̊ & 尺્ન & & 尺े̊ㅇ & $\stackrel{\circ}{\bar{\sigma}}$ & $\overline{\bar{\sigma}}$ & $\stackrel{\sim}{\stackrel{\sim}{\sim}}$ & $\stackrel{m}{\bar{\sim}}$ & $\underset{\nabla}{ \pm}$ & $\stackrel{n}{\frac{n}{\sim}}$ & $\stackrel{0}{\stackrel{0}{0}}$ & 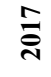 & $\stackrel{\infty}{\stackrel{\sim}{i}}$ & Freq. & $\%$ \\
\hline Protrusio & 10 & 6 & 11 & 2 & 9 & 5 & 12 & 3 & 2 & 5 & 3 & 8 & 4 & 5 & 4 & 5 & 94 & $66.67 \%$ \\
\hline Leucocoria & 1 & 3 & 3 & 3 & 3 & 3 & 6 & 3 & 3 & 4 & 1 & 2 & 2 & 3 & 3 & - & 43 & $30.50 \%$ \\
\hline Strabismus & - & - & - & 1 & - & - & - & 1 & - & - & - & 1 & - & 1 & - & - & 4 & $2.83 \%$ \\
\hline Total & 11 & 9 & 14 & 6 & 12 & 8 & 18 & 7 & 5 & 9 & 4 & 11 & 6 & 9 & 7 & 5 & 141 & \\
\hline
\end{tabular}

Based on table 4, most of the retinoblastoma patient was presented with protrusion of the eye $(66.67 \%)$, followed by leucocoria $(30.83 \%)$. Strabismus is the least frequent clinical symptom $(2.83 \%)$. We gave the questionnaire to patients family and obtained information regarding the reason behind delayed treatment. We concluded several main reasons involved; ignorance, the financial problem (low economic status, difficult access to health care facilities or worries. Table 5 showed the distribution of retinoblastoma patients based on the reason for delayed treatment with most of the reason is a financial problem (low economic status). 
Table 5. The reason for delayed treatment of retinoblastoma patients.

\begin{tabular}{|c|c|c|c|c|c|c|c|c|c|c|c|c|c|c|c|c|c|c|}
\hline Reason & ڤ్సి & ક્సે & 气ิ & ङ્ڤ & 今్ & $\stackrel{\infty}{\stackrel{్}{~}}$ & હેస్ & 옥 & $\overline{\bar{乛}}$ & ัㅗㄱ & 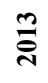 & $\stackrel{\Xi}{\vec{N}}$ & $\stackrel{n}{\stackrel{\sim}{\sim}}$ & $\stackrel{0}{\bar{ก}}$ & 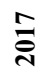 & $\stackrel{\infty}{3}$ & Freq & $\%$ \\
\hline Ignorance & 4 & 3 & 4 & 1 & 5 & 2 & 8 & 3 & 2 & 3 & - & 2 & 1 & 2 & - & - & 40 & $28.37 \%$ \\
\hline $\begin{array}{l}\text { Low } \\
\text { economic } \\
\text { (financial) }\end{array}$ & 5 & 5 & 7 & 3 & 6 & 3 & 6 & 3 & 1 & 3 & 3 & 7 & 4 & 5 & 4 & 4 & 69 & $48.94 \%$ \\
\hline $\begin{array}{l}\text { Difficult } \\
\text { access to } \\
\text { health care } \\
\text { facilities }\end{array}$ & 2 & 1 & 2 & 2 & 1 & 3 & 3 & 1 & 2 & 3 & 1 & 2 & - & - & 1 & 1 & 25 & $17.73 \%$ \\
\hline Worries & - & - & 1 & - & - & - & 1 & - & - & - & - & - & 1 & 2 & 2 & - & 7 & $4.96 \%$ \\
\hline Total & 11 & 9 & 14 & 6 & 12 & 8 & 18 & 7 & 5 & 9 & 4 & 11 & 6 & 9 & 7 & 5 & 99 & \\
\hline
\end{tabular}

We treated retinoblastoma patients based on the stage and extent of the diseases, including enucleation, exenteration, chemotherapy, exenteration combined with radiotherapy/ chemotherapy, enucleation combined with radiotherapy/ chemotherapy or radiotherapy/ chemotherapy alone. Table 6 shows a choice of treatment for retinoblastoma patients.

Table 6. The management of retinoblastoma patients.

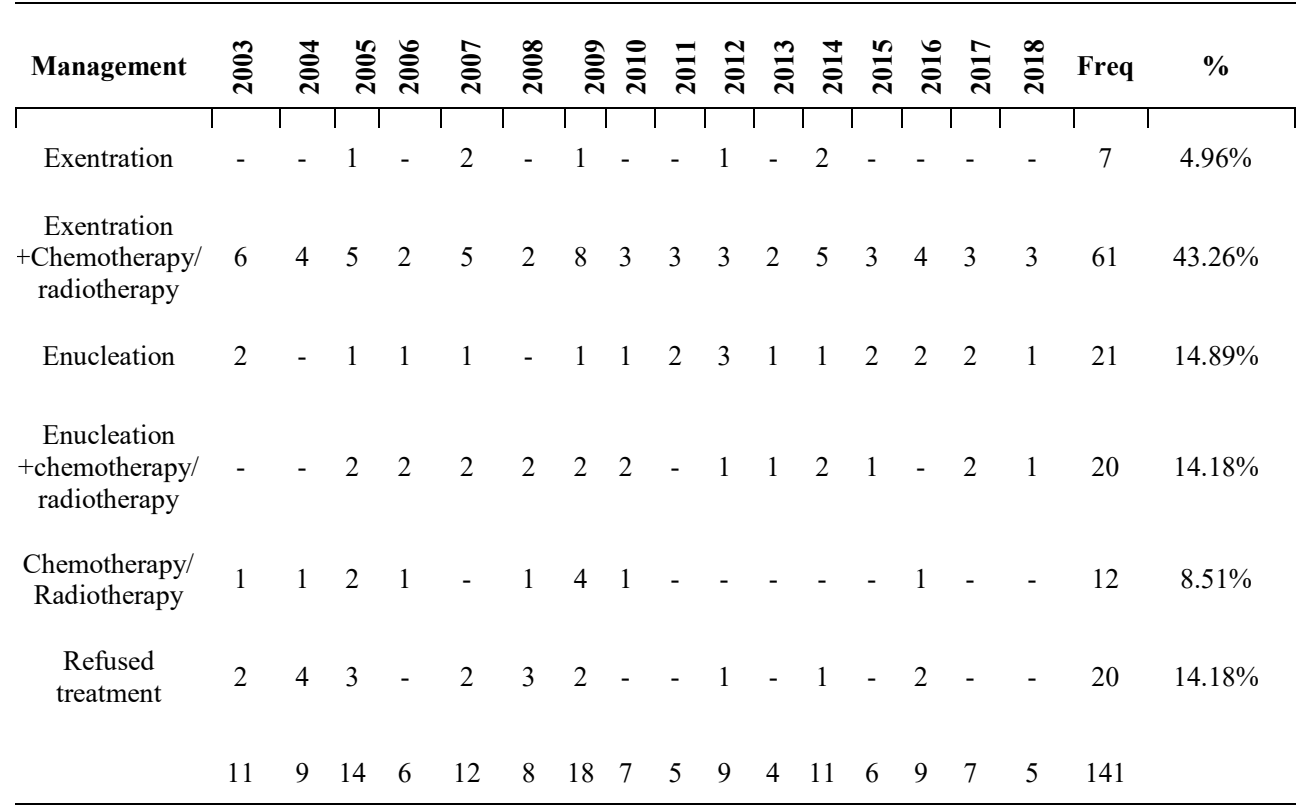

Based on table 6 , most of the patient was treated with exenteration in combination with either chemotherapy or radiotherapy. We assumed that this is caused by the delay in seeking treatment which caused delayed diagnosis and advanced stage of the disease during the first visit to the hospital. There were also 20 patients $(14.18 \%)$ who refused treatment due to several reasons. 


\section{Discussion}

Several previous studies of retinoblastoma found no predilection of gender and race, but in this study, we found that there were more male (56.73\%) than female (43.26\%) patients. Jamalia et al. and Soebagyo et al. in their study also found that retinoblastoma happened more in male than female patient, with a ratio of 1.6:1. [8]-[11]

In this study, most patients during the first visit were 3-4 years old (43.26\%) and followed by a group of $2-3$ years old $(28.39 \%)$. The result of this study had proved the delayed in seeking treatment thus patients were older during the first visit. In a study by Ausayakhun et al. and Soebagyo et al., it was found that the group age of 2-3 years old was the most frequent during the presentation. This late diagnosis was thought to be due to poor or less advanced screening methods in developing countries. [12],[13]

This study found higher unilateral involvement $(75.18 \%)$ of retinoblastoma. Lateralization of the affected eye according to Marjorie (1963-2004) in Swiss, found that $66.9 \%$ patients of retinoblastoma had unilateral involvement. Noguera et al. and Ausayakhun et al. also found cases with higher unilateral involvement as in $62.5 \%$ and in the occurrence of retinoblastoma rather than with hereditary $73.02 \%$ patients. It is shown that sporadic mutation more influenced mutation [13]-[15].

This study showed that patients were frequently presented with protrusion of the eye $(66.67 \%)$ and followed by leucocoria $(30.50 \%)$. The similar result was also obtained by Soebagyo et al. in their study in East Java, Indonesia where protrusion was the most frequent clinical symptom $(61.36 \%)$. However, this result is different with the result of another study in the countries of Southeast Asia region, where leucocoria was the most frequent clinical symptom $66.78 \%$. It showed that in our study, the patients generally came in an advanced stage and poor prognosis. Late diagnosis was due to other problems such as poor affordability and accessibility to available medical facilities. All of these contributes to the high mortality rate [12],[13],[15].

In term of a socioeconomic factor, we concluded several main reasons that caused the delay in seeking treatment. The main reasons included ignorance, financial disability (low economic status), difficult access to healthcare facilities, and worries. Most of the patient complained of the financial problem (48.94\%) that caused them to either delay seeking treatment in the first place or refuse to get any treatment. The second most frequent reason was ignorance $(30.50 \%)$. In this case, we concluded that these patients did not understand the information that we have regarding the disease, especially about the fatality of retinoblastoma and how it could affect patient's vision or worst, patient's life. We assumed that the educational status of parents was also in charge of this ignorance. Various studies have shown that patients with a lower socioeconomic status were less likely to receive the recommended therapy and experience less favorable outcomes as compared to those with a higher socioeconomic status.[12]

Low socioeconomy status and low education level were the reasons of patients are late in searching for help. Both factors are the main factor that causes for late diagnosis in a developing country, resulting in difficulty in making an early diagnosis. Noguera et al. also stated that financial problem $(71.4 \%)$ is the cause of late in seeking treatment in retinoblastoma patients in the Philippine [12],[14],[15]. 


\section{Conclusion}

$\mathrm{RB}$ accounts for a high tumor burden in developing countries, and the prognosis is closely related to the socioeconomic and cultural profile of the population. Socioeconomic and cultural factors directly affect disease progression and final treatment outcomes. These barriers can be overcome to a certain extent by improving awareness about the disease, proper counseling of parents, providing free of cost treatment to patients from low socioeconomic strata, and raising funds by involving government.

\section{References}

[1] Wright KW. Retinoblastoma and Other Malignant Intraocular Tumors. In. Handbook of pediatric Retinal Disease. Springer, New York. p.246-283

[2] Skuta GL, Cantor LB, Weiss JS (2013) Retinoblastoma. In: Ophthalmic Pathology and Intraocular Tumor. American Academy of Ophthalmology. San Fransisco p:178-181.

[3] Skuta GL, Cantor LB, Weiss JS (2012) Retinoblastoma. In: Strabismus and Pediatric Ophthalmology. American Academy of Ophthalmology. San Fransisco p: 354-365

[4] Kaiser PK, et al. (2009) Retinoblastoma. In: Digital Journal of Ophthalmology. Bascom Palmer Eye Institute University of Miami School of Medicine.

[5] Shield JA, Shield CR (2006) Clinical Overview: Retinoblastoma. IN: Ocular Oncology, Marcel Dekker New York p: 19-32.

[6] Ali MJ, Reddy VAP, Honavar SG, Naik M (2011) Orbital Retinoblastoma: Where Do We Go From Here? Journal of Cancer Research and therapeutics 7: 11-14.

[7] Quah BL (2005) Retinoblastoma. In: Clinical Ophthalmology an Asian Perspective. Elsevier Singapore p: 687-697

[8] Imbach P (2006) Retinoblastoma. In: Pediatric Oncology. SpringerVerlag Berlin p: 171-176.

[9] Naseripour M (2012) "Retinoblastoma Survival Disparity": The Expanding Horizon in Developing Countries. Saudi Journal of Ophthalmology 26: 157-161.

[10] De Camargo B, de Oliveira Ferreira JM, de Souza Reis R, Ferman S, de Oliveira Santos M, et al. (2011) Socioeconomic Status and the Incidence of Non-Central Nervous System Childhood Embryonic Tumours in Brazil 11: 1-6.

[11] Jamalia R, Sunder R, Alagaratnam J, Goh PP (2010) Retinoblastoma Registry Report - Hospital Kuala Lumpur Experience Med J Malaysia 65:128-30.

[12] Soebagjo HD, Prastyani R, Sujuti H, Lyrawati D, Sumitro SB (2013) Profile of Retinoblastoma in East Java, Indonesia. World Journal of Medicine and Medical Science Research 1: 51-6.

[13] Ausayakhun S, Ruankham $\quad$ P $\quad$ (1992) Epidemiology Study of Retinoblastoma in Maharaj Nakorn Chiang Mai Hospital. In: Current Aspects in Ophthalmology Philadelphia: Elsevier Science Publishers BV P: 57-62.

[14] Marjorie W, Balmer A, Munier F, Houghton S, Pampallona S, et al. (2006) Shorter Time to Diagnosis and Improved Stage at Presentation in Swiss Patients with Retinoblastoma Treated from 1963 to 2004. In: Pediatrics 118: 1493-1498.

[15] Noguera SI, Mercado GV, Santiago DE (2011) Clinical Epidemiology of Retinoblastoma at the Philippine General Hospital: 1998-2008. Philippine Journal of Ophthalmology 36: 28-32. 